\title{
Fine Needle Aspiration Cytology of Solitary Thyroid Nodule with Histopathology Correlation
}

\author{
Susmitha MS, Veena S*, Ramesh K Babu
}

Department Of Pathology. Shimoga Institute Of Medical Science. Sagar Road. Shimoga (India)

\section{ABSTRACT}

Background: Solitary thyroid nodule (STN) is a localized thyroid enlargement with apparently normal rest of the gland clinically. Preoperative Fine Needle Aspiration Cytology (FNAC) aids in distinguishing benign and malignant nodules and planning the treatment. Based on the cytology findings, patients can be followed in cases of benign diagnosis and thereby decreasing the rate of unnecessary surgery. However the accuracy of FNAC is found to be varied in different studies. The aim of the study was to study the cytological findings in STN and to correlate the FNAC and histopathology results.

Methods: A retrospective study including FNAC of 107 patients presenting with solitary thyroid nodule from January 2015 to June 2017 was done at Department of Pathology. Cytology and histopathology correlation was available in 40 cases.

Results: Solitary thyroid nodules involved females more commonly than males with a ratio of $10.8: 1$. Malignancy was present in $12.5 \%$ of cases and papillary carcinoma was the commonest malignancy. For malignancies, FNAC showed sensitivity of $40 \%$, specificity of $97.1 \%$, Positive predictive value of $66.6 \%$, Negative predictive value $91.9 \%$ and Efficacy of $90 \%$.

Conclusion: FNAC of solitary thyroid nodules has high specificity and efficacy. Low sensitivity of FNAC in STN necessitates caution and patient follow up in cases with cytological benign diagnosis.

Keywords: Thyroid, Nodule, Solitary, Cytology

\section{Introduction}

Solitary thyroid nodule (STN) is a localized thyroid enlargement with apparently normal rest of the gland clinically. The prevalence of thyroid nodules is $3-7 \%$ by palpation, $20-76 \%$ on basis of ultrasound and upto $50 \%$ at autopsy. Prevalence also depends on the regional iodine deficiency. It is up to $50 \%$ of adults in iodine deficient areas. It occurs more commonly in women than men. Malignancy is encountered more frequently in solitary nodules than multinodular goiters, with reported higher incidence in childhood STN than in adults. Malignancy occurs in approximately $5 \%$ of all the thyroid nodules. ${ }^{[1-6]}$

FNAC is a rapid, cost effective and reliable diagnostic tool for detecting malignancy in STN. Preoperative FNA plays a pivotal role in distinguishing benign and malignant nodules and treatment plan. Unnecessary extensive surgery and its related adverse effects, such as hypothyroidism, hypocalcemia and recurrent laryngeal nerve injury could be avoided. ${ }^{[2]}$ Radionucleotide scanning is the imaging technique useful in preoperative diagnosis of thyroid nodules, though unaffordable in many institutes. Ultrasound guided FNAC can be used for better sampling, especially in cystic and small lesions. The objective was to study FNAC findings in solitary thyroid nodules and correlate with histopathology.

\section{Materials and Methods}

A cross sectional study was done at Department of Pathology after obtaining approval from Institutional ethical committee. A retrospective analysis of cases and slide archives in the Department was done including cases from January 2015 to June 2017. Patients presenting with solitary thyroid nodule were included, irrespective of the thyroid profile status. Patients with diffuse thyroid enlargement and multiple nodules were excluded. FNAC was done using 23 guage needle and $5 \mathrm{ml}$ syringe under aseptic precautions. Non aspiration technique or aspiration by minimal negative pressure was followed in majority of cases. Smears fixed in ethanol and stained with Haematoxylin and Eosin stain (H\&E), Papanicolaou stain and air dried smears stained with Giemsa stain were analysed.

Histopathological examination of hemithyroidectomy, subtotal or total thyroidectomy cases with preoperative cytology diagnosis were included in the study. Histopathology and cytology results were correlated and analysed. Sensitivity, specificity, efficacy, positive and negative predictive values for neoplasms and malignancies were calculated.

\section{RESULTS}

FNAC of thyroid was done on a total of 378 patients. 107 cases presented with solitary thyroid nodule. It included 
9 male and 98 female patients. Age group of patients ranged from 18 to 75 years. Adequacy criterion of atleast 6 clusters, with 10-15 cells per cluster, was followed. Of the 107 cases, 2 FNACs had inadequate material and no opinion was possible. FNA results were as shown in Table1. Colloid goiter (28.9\%) (Fig 1.a,b), Colloid goiter with secondary changes(6.5\%), Nodular colloid goiter with cystic change(21.5\%), Nodular colloid goiter with adenomatous hyperplasia(14.7\%), Hashimotos thyroiditis (3.7\%).Follicular neoplasm constituted $8.4 \%$ of total cases (Fig 3). Papillary carcinoma (Fig.2), medullary carcinoma (Fig.1-c) and anaplastic carcinoma accounted for 3.7\%, $1.9 \%$ and $0.9 \%$ respectively. The most common neoplasm was Follicular neoplasm. The commonest malignancy was papillary carcinoma.

Histopathology correlation was available in only 40 cases (Table 2).Histopathologic evaluation showed Nodular colloid goiter in 27 cases(67.5\%), Follicular adenoma in 8 cases (20\%) (Fig.3-d), Papillary carcinoma in 4(10\%), Minimally invasive follicular carcinoma in 1 case $(2.5 \%)$.

Papillary Carcinoma Thyroid (PCT) - Tall cell variant showed Cells whose height were at least three times their width constituting $50 \%$ or more of papillary ca cells. Lesion was highly papilliferous with Invasion to skeletal muscle, showing PCT nuclear features .Nucleus located basally, with abundant oxyphilic cytoplasm and focal Sub nuclear clearing . (Fig.d,e,f) Minimally invasive follicular carcinoma showed microscopic, single capsular invasion. (Fig.3-e,f)

Results of cytology and histopathology with correlation were as shown in Table 2. In 30 cases, same diagnoses were given in both. Distribution of cases in non neoplastic and neoplastic category with correlation revealed 7 False negatives and 2 False positives for neoplasms, 1 false positive and 3 False negatives for malignancy (Table 3). 32 cases were diagnosed as non neoplastic lesions on cytology. On histopathologic evaluation of these cases,25nodular colloid goitre, 5 follicular adenoma, 2 papillary carcinoma were reported. 8 cases were diagnosed as neoplastic lesions by FNAC (4 follicular neoplasm, 1 hurthle cell neoplasm, 2 papillary carcinoma, and 1 medullary carcinoma). Among these, 2 non neoplastic lesions, 3 benign neoplastic lesions and 3 malignancies were reported on histopathology. As per these results, 1 False positive and 3 false negatives for malignancy, 2 False positives and 7 False negatives for thyroid neoplasms were noted.

Statistical analysis was done using the formulae. FNAC of solitary thyroid lesions showed sensitivity $40 \%$, specificity $97.1 \%$, Efficacy $90 \%$, Positive predictive value $66.6 \%$, Negative predictive value $91.9 \%$ for malignancies. For Neoplasms, FNA had Sensitivity 46.2\%, Specificity 92.6\%, Efficacy $77.5 \%$, Positive predictive value $75 \%$, Negative predictive value $78.1 \%$. (Table 4 )

Table 1: Cytological Diagnosis with percentage.

\begin{tabular}{|c|c|c|c|}
\hline S. No. & Diagnosis on cytology & No of cases(Total No $=107)$ & Percentage \\
\hline 1 & Colloid goiter & 31 & $28.9 \%$ \\
\hline 2 & Colloid goiter with secondary changes & 07 & $6.5 \%$ \\
\hline 3 & Nodular colloid goiter with cystic change & 23 & $21.5 \%$ \\
\hline 4 & Nodular colloid goiter with adenomatous hyperplasia & 16 & $14.7 \%$ \\
\hline 5 & Hashimotos thyroiditis & 4 & $3.7 \%$ \\
\hline 6 & Follicular neoplasm & 9 & $8.4 \%$ \\
\hline 7 & Hurthle cell neoplasm & 3 & $2.8 \%$ \\
\hline 8 & Suspicious for papillary carcinoma & 4 & $3.7 \%$ \\
\hline 9 & Suspicious for thyroid malignancy & 1 & $0.9 \%$ \\
\hline 10 & Papillary carcinoma & 4 & $3.7 \%$ \\
\hline 11 & Medullary carcinoma & 2 & $1.9 \%$ \\
\hline 12 & Anaplastic carcinoma & 1 & $0.9 \%$ \\
\hline 13 & No opinion & 2 & $1.9 \%$ \\
\hline
\end{tabular}

Table 2: Correlation of FNAC and Histopathology Diagnoses.

\begin{tabular}{|l|c|c|c|}
\hline FNAC Diagnosis & No. of cases & Histopathology diagnosis & No of cases \\
\hline \multirow{4}{*}{ Colloid goiter } & \multirow{4}{*}{31} & NCG with adenomatous hyperplasia & 7 \\
\cline { 2 - 4 } & \multirow{4}{*}{} & NCG with sec change & 8 \\
\cline { 2 - 4 } & & Follicular adenoma & 9 \\
\cline { 2 - 4 } & & Papillary carcinoma & 2 \\
\hline
\end{tabular}




\begin{tabular}{|l|c|c|c|}
\hline FNAC Diagnosis & No. of cases & Histopathology diagnosis & No of cases \\
\hline Hashimoto thyroiditis & 1 & Fodular goiter & 1 \\
\hline \multirow{2}{*}{ Follicular neoplasm } & \multirow{2}{*}{} & Colloid adenomatous goitre & 2 \\
\hline Hurthle cell neoplasm & 1 & Minimally invasive follicular carcinoma & 2 \\
\hline Papillary carcinoma & 2 & Papillary carcinoma & 1 \\
\hline Medullary carcinoma & 1 & Follicular adenoma & 2 \\
\hline & 40 & & 4 \\
\hline
\end{tabular}

Table 3: Distribution and correlation of cytology and histopathology lesions in STN.

\begin{tabular}{|l|c|c|c|}
\hline \multirow{2}{*}{ FNAC } & \multicolumn{3}{|c|}{ Histopathology } \\
\cline { 2 - 4 } & Non neoplastic & Benign neoplasm & Malignant \\
\hline Non Neoplastic & 25 & 5 & 2 \\
\hline Follicular/Hurthleneoplasm & 2 & 2 & 1 \\
\hline Malignant & 0 & 1 & 2 \\
\hline
\end{tabular}

Table 4: Statistical values for neoplastic and malignant lesions in STN.

\begin{tabular}{|l|c|c|}
\hline Statistical Index & Neoplasm & Malignancy \\
\hline Sensitivity & $46.2 \%$ & $40 \%$ \\
\hline Specificity & $92.6 \%$ & $97.1 \%$ \\
\hline Positive predictive value & $75 \%$ & $66.6 \%$ \\
\hline Negative predictive value & $78.1 \%$ & $91.9 \%$ \\
\hline Efficacy & $77.5 \%$ & $90 \%$ \\
\hline
\end{tabular}

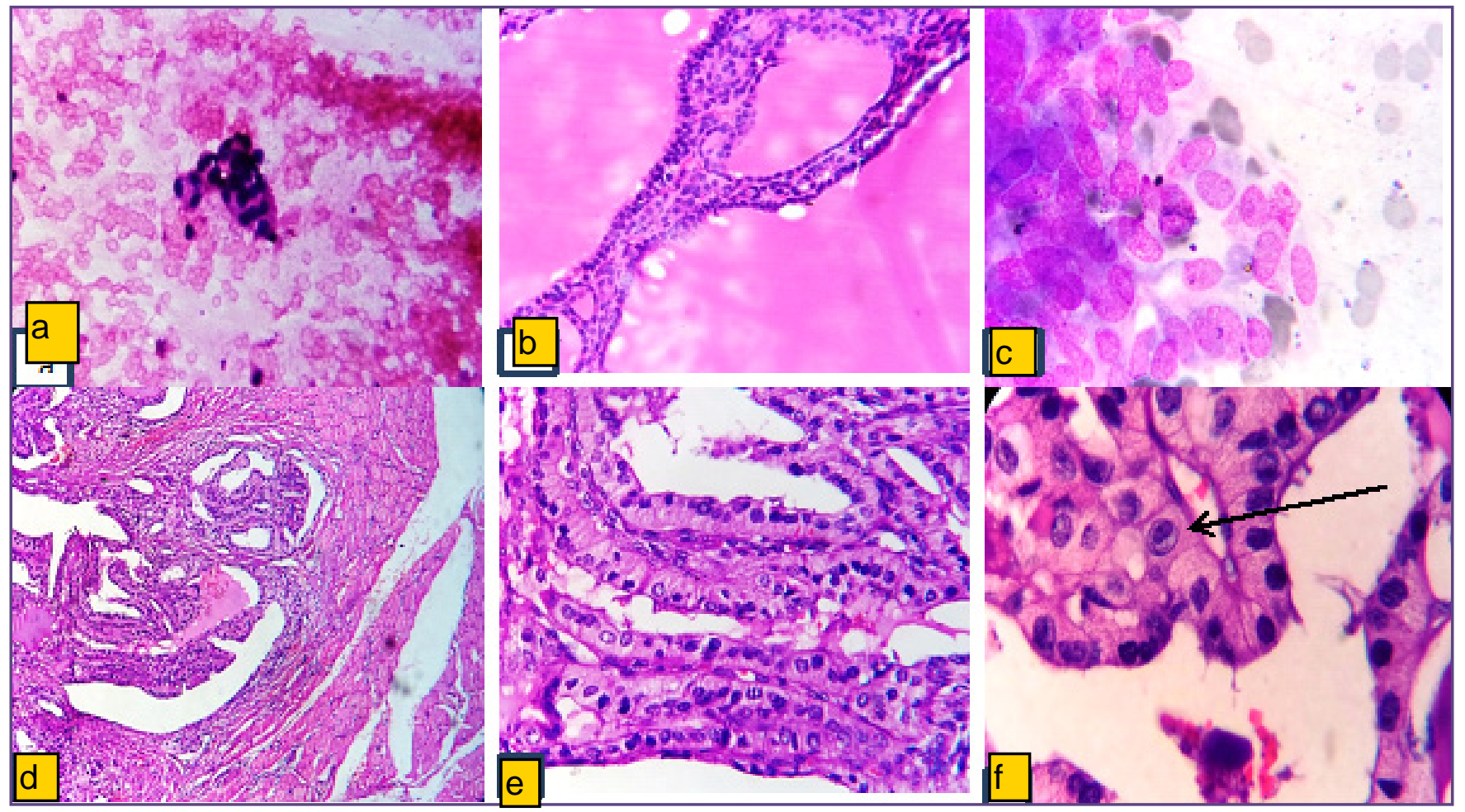

Fig. 1.a: colloid Goiter (H\&E x 400). b: histopathology of colloid Goiter (H\&E x400).c: shows cytology of medullary carcinoma thyroid with prominent paravacuolar granules (Giemsa x400).d -Tall cell columnar varient of papillary carcinoma thyroid(PCT) with skeletal muscle invasion (H\&E,x100), e - PCT (H\&Ex400),f- PCT showing intranuclear inclusions (H\&Ex400). 

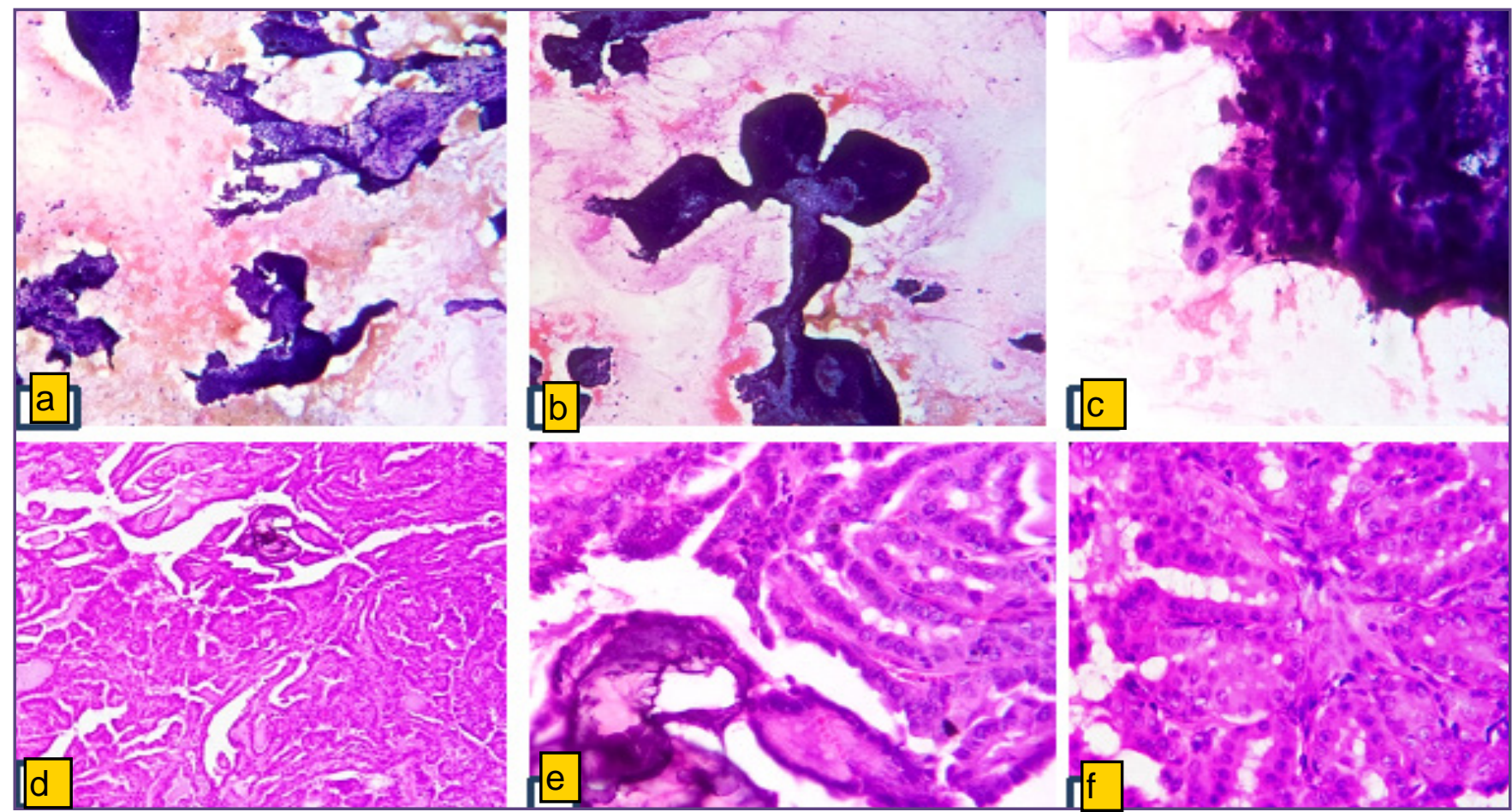

Fig. 2: a,b - cytology of papillary carcinoma thyroid (H\&Ex100), c- PCT (H\&Ex400).d - PCT (H\&E x100),e - PCT showing psammoma bodies \&f - PCT with complex papillary branching pattern, grooving and inclusions (H\&E x400).

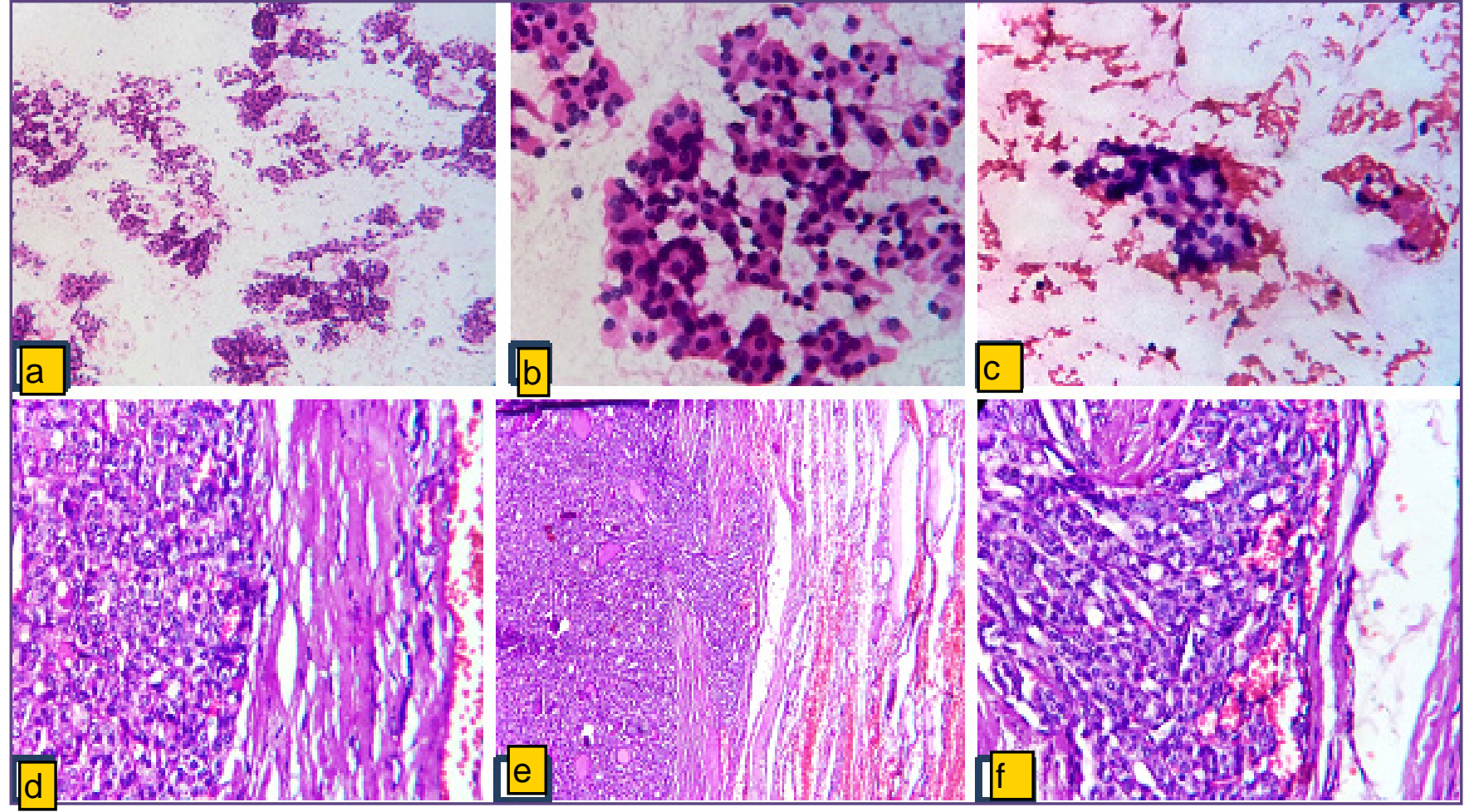

Fig. 3: a - Follicular neoplasm (H\&E x100) ,b,c - showing repetitive follicles in Follicular neoplasm (H\&Ex400). d- Histopathology of Follicular Adenoma(H\&Ex400).e,f-histopathology of minimally invasive follicular carcinoma with capsule on the right (H\&E x100 and x400). 


\section{Discussion}

FNAC is a simple, cost effective, rapid diagnostic test for thyroid nodules, with a significant role in determining the management of solitary thyroid nodules. FNA is useful in the detection of neoplasms in solitary nodules, that at times becomes challenging. Incidence of solitary thyroid nodules is about $5 \%$ in general population. STN are found to be more common in females compared to males. In our study female to male ratio was 10.8:1. Occurence of malignancy in the present study was $12.5 \%$. It was found to be $14.8 \%$ in study of Prakash et al., 10.8\% in SardaAK et al., 18\% in Kaur k et al., 4.1\% in Mundsad B et al, $46.2 \%$ in Jena et al, $18.5 \%$ in Anitha et al. ${ }^{[2,8-13]}$

Statistics showed 7 false negatives and 2 false positives for neoplasms, 1 false positive and 3 false negatives for malignancy. These are of concern. False positives usually are seen with Atypical or Follicular adenoma and colloid nodules. Paucicellularity, degenerative changes simulating malignancy are the other causes. ${ }^{[8,14,15]} 1$ follicular adenoma was misdiagnosed as medullary carcinoma on FNAC.

2 papillary carcinoma cases were misdiagnosed as non neoplastic on cytology( 1 nodular colloid goiter and 1 nodular colloid goitre with adenomatous hyperplasia on FNA). Histopathology of one of these cases showed papillary carcinoma and nodular colloid goiter in adjacent thyroid. The papillae and pseudo papillae can be seen in Papillary carcinoma, Grave's disease and hyperplastic nodule. Characteristic nuclear features such as nuclear grooves in more than $20 \%$ of follicular cells and presence of more than three intranuclear inclusions in the enlarged nuclei on single aspirate is pathognomonic of papillary thyroid carcinoma. Nuclear features and high cellularity are valuable in diagnosis of papillary carcinoma. But in cases with cystic change in papillary carcinoma, low cellularity and degenerative changes could be the causes for false negative result. Ultrasound guided FNA would help to reduce such false negatives by sampling the small foci of malignancy and avoiding nonmalignant parts of the lesion. Though only $10-15 \%$ of the cysts are neoplastic, FNA from solid area would reduce the misinterpretation and false negativity in cystic neoplasms. ${ }^{[16,17,18]}$

For malignancies, FNAC showed sensitivity of $\quad 40 \%$, specificity of $97.1 \%$, positive predictive value of $66.6 \%$, negative predictive value $91.9 \%$ and efficacy of $90 \%$. Previous studies on FNAC of solitary thyroid nodule have showed sensitivity and specificity of $68.1 \%$ and 100\%(Agarwal SK et al), 75\% and 100\% (Bapat et al), $89.4 \%$ and $99.2 \%$ (Gupta $\mathrm{C}$ et al), $40 \%$ and $100 \%$ (Prakash et al), $78.1 \%$ and $76.5 \%$ (Duek et al), $88.9 \%$ and 96.1\%(Nnagada et al), $86.1 \%$ and $59.7 \%$ (Chao et al),
$81.3 \%$ and $97.8 \%$ (Lopez et al) respectively. Efficacy of FNA in solitary thyroid nodule in the present study was $90 \%$, which is comparable with the previous studies. It was 95.7\% in Prakash et al, 92\% in Gupta et al., 94.5\% in Afroz et al., $87 \%$ in Kessler et al..$^{[6,8,19-26]}$

Akerman et al have quoted that the reasons for low sensitivity could be that tumor being missed at aspiration, misinterpretation of cytologic findings, cellular atypia, indeterminate diagnosis. ${ }^{[27]}$ The difficulty in cytological diagnosis in certain cases is attributed to overlap of cytological patterns between neoplastic and non- neoplastic lesions. The differentiation between adenomatous nodule and follicular neoplasm is difficult. Increased nuclear size and pleomorphism, cellularity, the presence of microfollicles, scant and thick background colloid increase the likelihood of accurately detecting neoplasms. Haemorrhagic aspirate with microfollicles is seen in follicular neoplasms because of high microvessel density in the nodule. ${ }^{[1,28]}$ Although many studies suggest features to differentiate the two, the diagnostic dilemma in interpretation of adenomatous hyperplasia and follicular neoplasm continues to concern.

\section{Conclusion}

FNAC of solitary thyroid nodules has high specificity and efficacy.It is one of the rapid, reliable, cost effective procedures for the diagnosis of thyroid malignancy and effective management. In view of false negative results, in cases with high clinical suspicion of malignancy, a non neoplastic diagnosis on FNAC should be viewed with caution and advised periodic follow up.

\section{Acknowledgement}

special thanks to medical research unit - MRU, SIMS, shimoga for their technical support.

\section{References}

1. Faquin WC. The Thyroid Gland.Recurring Problems in Histologic and Cytologic Evaluation. Arch Pathol Lab Med. 2008;132:622-632.

2. Jena A, Patnayak R, Prakash J, Sachan A, Suresh V, Lakshmi AY. Malignancy in solitary thyroid nodule. Indian J EndocrMetab. 2015;19:4:498.

3. Gupta M, Gupta S, Gupta VB. Correlation of fine needle aspiration cytology with histopathology in the diagnosis of solitary thyroid nodule. J Thyroid Res 2010:3.

4. Muratli A, Erdogan N, Sevim S, Unal I, Akyuz S. Diagnostic efficacy and importance of fine-needle aspiration cytology of thyroid nodules. J Cytol 2014;31:73-8.

5. Tai JD, Yang JL, Wu SC, Wang BW, Chang CJ. Risk factors for malignancy in patients with solitary thyroid nodules and their impact on the management. J Can Res Ther 2012;8:379-83. 
6. Gupta N, Goswami B, Hunjan PS, Shankar LR and Kakar A. Evaluation of the clinicopathological profile of solitary thyroid nodules: Our experience. Thyroid Res Pract.2016;1-12.

7. Nadgouda VG. Approach to a Patient with Solitary Thyroid Nodule. Medicine Update 2011;185-90.

8. Muddegowda PH, Lingegowda JB, Hiremath SS, Kishanprasad HL, Nagesh T, Joshua. Panorama of solitary thyroid nodule. Int $\mathbf{J}$ Med Health Sci. January 2012;1(1):19-26.

9. Sarda AK, Gupta A, Jain PK, Prasad S. Management options for solitary thyroid nodules in an endemic goitrous area. Postgrad Med J 1997; 73:560-4.

10. Kaur K, Sonkhya N, Bapna AS, Mital P. A comparative study of fine needle aspiration cytology, ultrasonography and radionuclide scan in the management of solitary thyroid nodule: A prospective analysis of fifty cases. Ind $\mathrm{J}$ Otolaryngol head neck surg 2002 June; 54(2):96-101.

11. Mundasad B, Mcallister I, Carson J, Pyper PC. Accuracy of fine needle aspiration cytology in diagnosis of thyroid swellings. In: The internet journal of endocrinology 2006.

12. Anitha S, Ravimohan TR. A study of incidence of malignancy in solitary nodule of thyroid. International Journal of Contemporary Medical Research 2016;3(4):993-995.

13. Das DK, Khanna CM, Tripathi RP, Pant CS, Mandal AK, Chandra $\mathrm{S}$ et al. Solitary nodular goitre-Review of cytomorphologic features in 441 cases.ActaCytol 1999; 43:563-74.

14. Nguyen GK, Lee MW, Ginsgerg J, Wragg T, Bilodeau D et al. Fine needle aspiration of the thyroid: an overview. Cytojournal 2005; 2:12-16.

15. Hay ID. Thyroiditis: a clinical update. Mayo ClinProc 1985; 60:836-43.

16. Bommanahalli BP, Bhat RV, Rupanarayan R. A cell pattern approach to interpretation of fine needle aspiration cytology of thyroid lesions: A cyto-histomorphological study. J Cytol 2010;27(4):127-32.

17. Sukumaran R, Kattoor J, Pillai KR, Ramadas PT, Nayak N, Somanathan $T$ et al. Fine Needle Aspiration Cytology of Thyroid Lesions and its Correlation with Histopathology in a Series of 248 Patients. Indian J Surg Oncol.2014;5(3):237-241.
18. Ersoz C, Firat P, Uguz A, Kuzey GM. Fine-needle aspiration cytology of solitary thyroid nodules: how far can we go in rendering differential diagnoses? Cancer 2004;102:302-7.

19. Aggarwal SK, Jayaram G, Kakar A, Guel GD, Prakash R, Pant CS. Fine needle aspiration cytologic diagnosis of the solitary cold thyroid nodule - comparison with ultrasonography, radionuclide perfusion and xeroradiography. ActaCytol 1989; 33(1):41-7.

20. Bapat RD, Shah SH, Relekar RG, Pandit A, Bhandarkar SD. Analyis of 105 uninodulargoitres. J Postgrad Med 1992; 38:60-1.

21. Duek SD, Goldenberg D, Linn S, Krausz MM, Hershko $\mathrm{DD}$. The role of fine-needle aspiration and intraoperative frozen section in the surgical management of solitary thyroid nodules.Surg Today 2002; 32(10):857-61.

22. Nnagada HA, Musa AB, Gali BM, Khalil MIA. Fine needle aspiration cytology of thyroid nodules: A Nigerian tertiary hospital experience. The internet journal of Cardiovascular Research 2006.

23. Chao CT, Lin JD, Chao HH, Hsueh C, Chen MF.Surgical treatment of solitary thyroid nodules via fine needle aspiration biopsy and frozen section analysis. Ann SurgOncol 2007; 14:712-8.

24. Lopez H, Montano AS, Acosta TEM, Ramirez ZFR, Torres DRM, Ruiz AP et al. Combined use of fine-needle aspiration biopsy, MIBI scans and frozen section biopsy offers the best diagnostic accuracy in the assessment of the hypofunctioning solitary thyroid nodule. Eur J Nucl Med MolImag 2004 Sept; 31(9):1273-9.

25. Afroze N, Kalyani N, Hasan SH. Role of fine needle aspiration cytology in the diagnosis of palpable thyroid lesions. Indian J PatholMicrobiol 2002 July;45(3):241-6

26. Kessler A, Gavriel H, Zahav $S$ et al. Accuracy and consistency of fine-needle aspiration biopsy in the diagnosis and management of solitary thyroid nodules," Israel Medical Association Journal 2005;7(6):371-373.

27. Akerman M, Tennvall J, Biorklund A, Martennson H, Moller T. Sensitivity and specificity of fine needle aspiration cytology in the diagnosis of tumors of the thyroid gland. ActaCytol 1985; 29:850-5.

28. Lingegowda JB, Muddegowda PH, Rajesh KN, Kurpad RR. Application of pattern analysis in fine needle aspiration of solitary nodule of thyroid.J Cytol 2010;27(1):1-7.

\section{*Corresponding author:}

Veena S, Department of pathology. Shimoga institute of medical science. Sagar road. Shimoga Karnataka 577201((India)

Phone: +91 08182229933

Email: drveenas82@gmail.com

Financial or other Competing Interests: None.

Date of Submission : 28.07.2017

Date of Acceptance : 17.08.2017

Date of Publication : 22.12.2017 